\title{
A ASCENSÃO DA CONCEPÇÃO CARTESIANA AO JORNALISMO
}




\section{A ASCENSÃO DA CONCEPÇÃO CARTESIANA ${ }^{1}$ AO JORNALISMO}

Resumo: A partir de uma pesquisa bibliográfica, o presente artigo busca problematizar historicamente a construção do preceito de verdade objetiva enquanto elemento fundante das práticas profissionais no jornalismo brasileiro a partir de meados do século XIX. Para isso, analisa-se a imbricação entre a constituição epistemológica moderna da noção de verdade em Descartes, Comte e em autores do Círculo de Viena e a concepção de objetividade jornalística no processo de empresariamento midiático no Brasil.

Palavras chave: Objetividade; verdade; ciência; jornalismo empresarial

\section{LA ASCENCIÓN DE LA CONCEPCIÓN CARTESIANA AL PESIODISMO}

Resumen: Desde una búsqueda bibliográfica, este artículo busca problematizar la construcción histórica del precepto de verdad objetiva como un elemento fundante de las prácticas profesionales en el periodismo brasileño desde el siglo XIX. Para eso, se analisa la imbricación entre la constitución de la noción epistemológica moderna de verdad en Descartes, Comte y en los autores del Círculo de Viena y el concepto de objetividad periodística en el proceso de 'empresariamiento' de los medios de comunicación en Brasil.

Palabras clave: Objetividad; verdad; ciencia; periodismo empresarial

\section{THE RISE OF CARTESIAN CONCEPTION IN JOURNALISM}

Abstract: Using a bibliographic research as starting point, this article seeks to problematize historically the construction of the precept of objective truth as a foundational element of the professional practices in Brazilian journalism since the 19th century. For this we analize the imbrication between constitution of the modern epistemological notion of truth in Descartes, Comte and the authors of the Vienna Circle and the conception of journalistic objectivity in the process of media business in Brazil.

Keywords: Objectivity; truth; science; business journalism

1 O termo 'concepção cartesiana' não está limitado aos apontamentos de René Descartes, pois somente o cartesianismo proposto por este não dá conta da multiplicidade de variáveis que conformaram o pensamento científico moderno que tanto influenciou o método jornalístico. Desta forma, a terminologia será utilizada tendo o pensamento de Descartes como ponto de partida que traduz questões chave para a formulação da ciência moderna enquanto objetiva, clara e racional, e não se limitando às proposições do filósofo francês. 
CADERNOS DE COMUNICAÇÃO (V.16, N.2, JUL-DEZ 2012)

Nem a ciência nem a racionalidade são medidas universais de excelência. São tradições particulares, não tendo consciência de sua base histórica.

Paul K. Feyerabend

Pode-se ter objetividade, mas o modelo não provém do objeto, e sim da ação criativa da mente.

David Bohm

Em meio à consolidação da cosmovisão moderna no Ocidente, o conhecimento científico ganha cada vez mais relevância. Desde o século XVII, a ciência veio se formatando a partir de filósofos como René Descartes, que acreditava ter a missão de unificar todos os conhecimentos humanos a partir de bases seguras que conformariam uma 'ciência admirável', iluminada pela verdade e pelas certezas racionais. Insatisfeito com a falta de fundamentação racional da área das humanidades e com a não aplicação do conhecimento matemático a problemas da vida, Descartes buscava a verdade dos conceitos por meio de demonstrações físicas e matemáticas - consideradas por ele como as únicas indubitáveis -, atualizando o ideal pitagórico de submeter o universo aos números (GRANGER, 1979).

Nesse sentido, o filósofo procura a todo custo ultrapassar qualquer incerteza, propondo a dúvida hiperbólica como método para se chegar à claridade da razão. Frente à hipótese de sermos enganados por um gênio maligno que conduz ao erro e a não objetividade do mundo físico, Descartes propôs a existência de um bom Deus que, sendo bom, a imagem que o homem faz do mundo exterior não é uma invenção de sua mente. Desta forma, se Deus existe como garantia da objetividade, é efetiva a certeza de que o mundo físico é real. Assim, o pensamento oferece ao espírito, através da dúvida metódica, um conjunto de regras para se chegar ao conhecimento verdadeiro tendo em vista que o conhecimento sensível é causador de erro, e a verdade é atingida através do intelecto.

Na obra Discurso do Método, Descartes tem como preceito metodológico que só o que for evidente pode ser considerado verdadeiro, e propõe também preceitos complementares ao método cartesiano, tais como: o preceito de análise, o da síntese e o da enumeração. O primeiro sugere a divisão das dificuldades que se apresentam em quantas partes forem necessárias para sua resolução; o segundo assinala que é necessário conduzir ordenadamente o pensamento, iniciando pelos objetos mais fáceis até chegar aos mais complexos; já o último propõe a enumeração como forma de conferir se nada foi omitido. 
No século XIX, período de transição do jornalismo, desponta o Positivismo de Auguste Comte, o qual expressa um tom geral de confiança nos benefícios da industrialização e de otimismo em relação ao progresso capitalista, cultuando a ciência e o método científico como diretrizes filosóficas. Para Comte, a sociedade se movia por meio de três etapas progressivas: a teológica ou fictícia seria a primeira, representando o ponto de partida da inteligência humana; a etapa metafísica ou abstrata expressa a transição para o último e mais evoluído estágio, chamado de científico ou positivo, no qual a proposição de leis universais traduz o progresso racional e maduro da humanidade (COTRIM, 1996). Dessa forma, o objetivo do método positivo é a investigação das leis gerais que regem os fenômenos naturais e sociais, a fim de tornar o homem capaz de prevê-los e atuar sobre a realidade.

As características fundamentais do Positivismo são a ênfase na pesquisa de fatos concretos e reais; a investigação de assuntos úteis e destinados ao aperfeiçoamento individual e coletivo; a valorização da certeza e o abandono das dúvidas e da discussão metafísica; a busca pela precisão no conhecimento a fim de que este não contenha ambiguidades; a organização como forma de sistematizar a produção cientifica; e a relatividade para que a ciência se aperfeiçoe e evolua ao longo do tempo. Desse modo, iniciando pelos fenômenos mais gerais e simples aos mais complexos e específicos, Comte classificou hierarquicamente o conhecimento científico partindo das ciências exatas à biologia e, por último, à sociologia - termo criado pelo filósofo o qual diz respeito ao estudo da psicologia, da ética, do direito, da economia, dentre outros. Assim, o projeto de reforma social positivista - o amor por princípio, a ordem por base e o progresso por fim - tinha por meta restabelecer, de forma conservadora, a ordem na sociedade capitalista industrial partindo da reorganização intelectual, moral e, por fim, política.

Influenciado por estas ideias e por filósofos como Wittgenstein, Russell e Whitehead, o Círculo de Viena é criado em 1928 com o fim de investigar qual a medida de veracidade das teorias a partir de suas estruturas lógicas. Considerado como representante da tendência neopositivista ou do empirismo lógico, os integrantes deste grupo propunham a superioridade da lógica, da matemática e das ciências empíricas e o princípio de verificabilidade como guia para se atingir o verdadeiro conhecimento, formando um: 
[...] grupo de cientistas, lógicos e matemáticos que tinham em comum a total ojeriza pelo arbitrário da filosofia e da metafísica. Em suma, eles queriam que a filosofia, o pensamento, refletisse a imagem da ciência, isto é, que houvesse enunciados dotados de sentido, e que fossem baseados no que é observável e verificável (MORIN, 2003, p. 37).

No contexto político da primeira metade do século $X X$, as duas guerras mundiais impulsionaram o desenvolvimento da Teoria da Comunicação, pois viam nesta a possibilidade de se estudar a influência da propaganda. Desde 1933, com a ascensão do nazismo, os Estados Unidos receberam diversos intelectuais que se refugiavam do regime totalitário alemão, favorecendo o estudo acadêmico da Ciência da Comunicação (AMARAL, 1996). Dessa maneira, sob a influência do paradigma da precisão, surge nos Estados Unidos, na década de 30, o modelo de comunicação de Lasswell, o qual desenvolvia o seguinte processo comunicativo: quem diz o que em que canal a quem com que efeito. Complementando o modelo aristotélico - comunicador, mensagem e receptor - o modelo de Lasswell foi amplamente utilizado nas análises políticas sobre a formação e difusão dos símbolos de legitimidade do governo.

Já o modelo de Shanonn e Weaver (1947), criado para explicar a comunicação entre máquinas, teve seu uso adaptado à comunicação humana. Também coerente com a proposta aristotélica, foi bastante criticado por seus autores serem engenheiros que entendiam a comunicação como uma troca de informação e dados na qual um comunicador emite uma mensagem que é transformada em sinais por um transmissor até chegar a um canal. A partir daí, os sinais são recebidos e decodificados por um receptor que leva a mensagem até um destinatário. Nesse sentido, são evitadas as possibilidades de ruído - entendido como distorção e erro - durante o processo de transmissão da mensagem que, a partir do mecanismo de feedback, permite a fonte controlar o modo como o destinatário está recebendo as informações.

Assim, a tentativa de encerrar a comunicação em uma esfera técnica e científica foi recorrente (e ainda é até hoje). Exemplo disso foi a proposta da 'Ciência Jornalística', de Otto Groth (apud MEDINA, 1988), a qual postula que a informação jornalística está regida por leis que dizem respeito às relações funcionais existentes entre periodicidade, universalidade, atualidade e difusão, consideradas como características intrínsecas a jornais, revistas e folhetos. Desse modo, Groth propõe cinco leis ao fenômeno da comunicação: 1) quanto mais amplamente se utilize a Universalidade na matéria de um periódico, mais extensa será 
a difusão do mesmo e sua acessibilidade geral quanto ao número de leitores, ou seja, a Difusão é uma função da Universalidade, $D=f(U) ; 2)$ quanto mais Atualidade se queira dar a matéria de um periódico, mais frequentemente deverá ser publicado. Desta forma, a Periodicidade é uma função da Atualidade, $P e=f(A) ; 3$ ) quanto mais intensa ou extensa seja a Acessibilidade do periódico, mais extensa deve ser sua Universalidade, por conseguinte, $U=f(D)$; 4) quanto mais curtos forem determinados períodos entre duas edições de um periódico, mais frequente aparecerá e mais atual será a matéria, isto é, $A=f(P e)$; assim, a última lei combina a Universalidade e a Atualidade para designar as seguintes fórmulas: quanto mais Universal e Atual for um periódico, mais frequentemente deve aparecer, $\mathrm{Pe}$ $=f(U A)$, e maior será a acessibilidade geral, $D=f(U A)$, ou seja, Pe $D=f(U A)$.

Para Contrera (2009), esta concepção utilitarista e maquínica de Comunicação promove o triunfo da quantidade em detrimento da qualidade, da funcionalidade em detrimento do significado, da eficiência frente à criatividade e à livre experimentação, acarretando pelo menos três consequências: a) a supervalorização de medidores de impacto como índices de audiência, ao invés da significância; b) a ampla difusão e importância da funcionalidade tecnológica dos meios de comunicação frente ao restrito debate sobre o impacto semiótico e psico-afetivo desses meios junto à sociedade; e c) a padronização e a velocidade de circulação da informação-mercadoria em meio à imposição da máquina funcional da grande mídia.

Assim, não é à toa que o jornalismo assume a roupagem da objetividade e qualifica, segundo Medina (1988), a notícia a partir de princípios como factualidade, atualidade, veracidade, interesse por parte do público e clareza. Buscando atingir a 'verdade' a partir da credibilidade do método científico, a imparcialidade é assumida como fundamental à prática do bom jornalismo, que não mais se balizaria em opiniões e sensações que conduzem ao erro e que são contaminadas por crenças e ideias acumuladas ao longo do tempo. Barros (2007) assinala que:

[...] apropriando-se de princípios da racionalidade moderna, também o Jornalismo (enquanto teoria e prática) desenvolveu um discurso desencantado, incompatível com as falas normais da vida. Também o Jornalismo reduziu o rigor ao rigor matemático (basta observar a importância dos números nas reportagens) e promoveu a especialização. Neste último caso, é notória a aquisição de linguagens especializadas pelo jornalista e a multiplicação de cadernos de jornais direcionados a públicos segmentados (BARROS, 2007, p. 3). 
Amaral (1996) aponta que o advento das agências de notícias, o desenvolvimento industrial, as duas guerras mundiais e a instauração da publicidade e da propaganda contribuíram para a consolidação do jornalismo enquanto atividade objetiva. Segundo o autor, as agências de notícias foram inicialmente direcionadas a governos, banqueiros, diplomatas, armadores e transportadores, com a função de lhes oferecer notícias por atacado. Com o tempo, os jornais se tornaram clientes em busca de notícias, as quais, para atenderem tanto aos antigos clientes como aos jornais, passaram a ter um certo grau de imparcialidade com a imposição de um noticiário equilibrado que buscasse contemplar todos os lados da questão. Contudo, para que a prática da objetividade se instalasse enquanto padrão foi necessária a ampliação do público leitor, fator relacionado ao desenvolvimento industrial.

Nesse sentido, o autor assinala que o desenvolvimento da penny press ${ }^{2}$, nos Estados Unidos da década de 1830, consolidou o conceito de notícia enquanto direcionada ao que acontecia no dia-a-dia da comunidade, "seus dramas, alegrias e decepções, pela história de interesse humano, espetáculos, crimes, casamentos e esportes" (AMARAL, 1996, p. 30). Ainda que essa concepção de notícia fosse rejeitada por diversos setores da imprensa da época3, o tamanho dos empreendimentos jornalísticos neste modelo tornou inviável o jornalismo de cunho pessoal tendo em vista o aumento de vendas diárias dos periódicos que seguiam aquela orientação. Assim, a ideia da nova política era:

[...] ]oferecer aos leitores e ao mercado notícias selecionadas e escritas em um tom desapaixonado que não parecesse ficção, propaganda ou panfleto. Os repórteres foram advertidos a não injetarem opiniões e preconceitos nas matérias, uma prática de sinal fechado para qualquer tipo de questionamento (AMARAL, 1996, p. 30).

Dessa forma, o surgimento da empresa jornalística no Brasil data, segundo Medina (1988), de meados de 1890. A autora aponta duas tendências nesta transformação: a primeira diz respeito à adaptação e modernização de periódicos que vivenciam esse momento de transição, tais como Gazeta de Notícias

2 Jornal de penny, jornal-centavo, barato, popular, segundo Amaral (1996).

3 Exemplos disso são a recusa do jornal Tribune em publicar notícias de crimes e escândalos e a reação do jornal Courier and Enquirer afirmando que homem de bem não compra jornal no meio da rua, mas sim o recebe em sua casa, via assinatura (AMARAL, 1996). 
e Jornal do Comércio, e outros que já nascem com uma estrutura empresarial voltada para o lucro, como Jornal do Brasil e Correio da Manhã. Com o objetivo de conquistar um público cada vez mais amplo, o jornal empresa passou a considerar preferencialmente o gosto do leitor:

A ênfase recai sobre o que o público quer e não sobre a opinião do grupo que manipula o jornal. Surge, então, pouco a pouco, o jornal noticioso, que logo se transforma em sensacionalista; surge também a crônica esportiva, policial e social (MEDINA, 1988, p. 47).

A urbanização e a industrialização são os fatores históricos que impulsionaram estas mudanças na imprensa brasileira que, para sua implantação, exigiu o surgimento de populações urbanas e com certo poder aquisitivo (MEDINA, 1988). Dessa forma, a tipografia perde seu caráter artesanal e assume lugar em linhas de produção com aparelhamento técnico e manipulação competente. Inovações mecânicas, divisão do trabalho, especialização, racionalização de custos, conquista de mercados e ampliação da indústria gráfica são fatores de paulatina transformação dessa nova fase (BAHIA, 1990). O autor assinala que os editores de jornais e empresários gráficos compreendem que o jornalismo mais literário e político já não atende as exigências da época.

A distribuição, por sua vez, torna-se cada vez mais complexa, abarcando assinantes, vendas avulsas, leitores locais, nacionais e do exterior. A revista $\mathrm{O} C r u-$ zeiro4 ${ }^{4}$ passa a ser distribuída nacionalmente desde 1928. Os jornais regionais se expandem em diversos Estados do país, tais como Rio de Janeiro, São Paulo, Rio Grande do Sul, Pernambuco, Bahia e Minas Gerais. Segundo Bahia (1990), a especialização da imprensa também surge como estratégia de conteúdo, tendo como exemplo o periódico Chácaras e Quintais que, em 1910 abre um ciclo de produção sofisticada entre os veículos que cobrem agricultura. Além disso, inaugura-se por volta de 1913 o uso do placar de informações - já comum na Europa e Estados Unidos - que visa atrair a atenção dos leitores para os conteúdos dos jornais e também mantê-los atualizados das notícias do dia mesmo quando a edição já está esgotada. Assim, Bahia (1990) assinala que a competição entre jornais por

4 Conforme Bahia (1990), a temporalidade da revista de Assis Chateaubriand está relacionada às mudanças da época, as quais viabilizaram a convivência com a velocidade do avião, o alcance da radiotelefonia, a extensão do correio aéreo, o conforto individual do automóvel, as grandes estruturas de cimento e a imagem do novo mundo. 
tiragens e circulação e a instalação de balcões de classificados estimulam escritórios de publicidade, ampliando a cobertura com prioridade para a reportagem e reservando verbas no balanço anual para o reaparelhamento editorial.

Nesse sentido, as inovações tecnológicas que acompanharam a industrialização da imprensa no século XX também são fatores que contribuíram para estas transformações. Na Primeira Guerra Mundial (1914 - 1918), o telégrafo ganha cada vez mais importância na transmissão das notícias sobre o conflito, mas devido à limitação deste aparelho, a linguagem antes rebuscada e adjetivada passa a ser o mais econômica possível. Assim, são importadas do modelo estadunidense fórmulas como o lead - o quê?, onde?, como?, quem?, quando? - e o modelo da pirâmide invertida, que prevê a redação do texto jornalístico partindo do considerado mais importante ao menos significativo, ao contrário do modelo anterior do nariz de cera. É importada também a ideia do copy-desk, espécie de redator responsável por reescrever as matérias a fim de limpar os textos e dar um ar jornalístico aos press releases recebidos pela redação: "era o homem encarregado de acabar com a literatice" (AMARAL, 1996, p. 75). Assim, a política nacional sai das manchetes dos jornais para dar espaço às informações que chegavam sobre a guerra, consolidando a imprensa de periodicidade diária e não-regional. Em meio ao paulatino crescimento de agências de notícias's, surgem também os primeiros correspondentes internacionais e a perseguição pelo furo jornalístico tendo em vista que, a empresa que o obtivesse, venderia mais.

Desse modo, a grande indústria da informação exige a profissionalização dos técnicos que lidam com a notícia - tratada a partir de então como um produto - com o fim de disciplinar o aprendizado do ofício jornalístico. Há, então, uma explosão de livros técnicos e manuais que buscam tratar teoricamente desta 'nova' área de conhecimento:

Com a evolução das empresas jornalísticas, aparece outro ramo de estudos essencialmente pragmático, centralizado na eficiência técnica. Parte, sobretudo, de profissionais ou semiprofissionais, a busca de uma teorização imediatista do fazer jornalístico. São embriões de manuais ou os compêndios que levantam o processo técnico da informação ao nível do código verbal (MEDINA, 1988, p. 16).

5 São apontadas como primeiras agências de notícias a Havas, em 1835; mais tarde a France Presse; a Harbour News Association, 1848, formará a futura Associated Press; a Telegraphen Compagnie de Berlim, de 1849; e a Reuters, criada em 1851. 
A partir dos anos 1950, consolida-se a modernização da imprensa brasileira, marcada pelo empresariamento. Desde a década de 1920, o rádio já estava presente, iniciando um processo de concentração industrial com a formação de cadeias de empresas jornalísticas. Essa concentração foi aprofundada tanto em termos administrativos quanto de conteúdo quando Assis Chateaubriand traz a televisão ao Brasil, formando a TV Tupi. Emergem no mercado grandes empresas de comunicação com ambição de se expandir em âmbito nacional, como a Bloch (Manchete e Fatos \& Fotos) e a Editora Abril (Realidade e Veja), cujos produtos empregam ingredientes similares aos internacionais:

A revista Fatos \& Fotos se transforma numa versão cabocla da Life norte-americana. O Jornal do Brasil funda, em 1964, seu Departamento de Pesquisa e Documentação, segundo modelo do New York Times, que se propõe acrescentar os dados à notícia (MEDINA, 1988, p. 66).

Desta forma, Fonseca (2005) assinala que a década de 1950 constitui um verdadeiro marco na história da imprensa, pois assinala a virtual superação da fase do 'jornalismo literário' e a entrada em definitivo nos quadros do chamado 'jornalismo empresarial'. A transformação do jornal e da notícia em produto é fenômeno circunscrito à etapa monopólica, ainda que tardia, do capitalismo brasileiro. Nesse sentido, o jornalismo se consolida como negócio no Brasil nos an1os 1960. Daí em diante, institucionaliza-se como tal e se organiza em conglomerados privados nacionais que atuam conforme a lógica do regime de acumulação e sob a vigilância do Estado, então sob o controle burocrático-autoritário dos militares.

Esta nova ordem foi viabilizada de forma dependente e através da associação do Estado e dos grupos dominantes nacionais com o capital estrangeiro, que aqui passou a investir maciçamente, principalmente depois do Golpe de 1964. A produção jornalística, meio de acesso à realidade social de crescente importância nas sociedades urbanas e industriais, assim como instrumento de formação de opinião, não ficou imune à lógica dominante. Desta forma, a natureza de produto conferida às informações jornalísticas se conforma com a preocupação de tornar as notícias mais acessíveis e sedutoras ao público. Estes são alguns dos sintomas das transformações ocorridas, assim como a oligopolização e a concentração de propriedade, capital e tecnologia. Nesse sentido, o jornalismo é sujeitado à lógica empresarial através de estratégias como a centralização da produção, a hierarquização e especialização de funções, a integração dos setores administrativo, editorial e industrial, além do 
aumento de espaço à publicidade e do texto pouco aprofundado das matérias e reportagens (TASCHNER apud FONSECA, 1992).

Em meio a esse contexto, teorizou-se que os interesses do público circulam ao redor de aspectos como emoções, superação, dinheiro ou propriedade, sexo, interesse local e importância social. Partindo do critério de seleção da notícia e sua relação com o gosto do público, em 1968, é postulada uma pirâmide de interesses previsíveis que um bom editor deve considerar:

[...] proeminência, celebridade das pessoas envolvidas nos fatos; importância das consequências; raridade do acontecimento, animação vital e interesse humano; rivalidade, conflito ou luta que o fato pressupõe; utilidade imediata do serviço informativo; entretenimento que proporciona (QUIROS apud MEDINA, 1988, p. 21).

Ampliando ainda mais a fragmentação no jornalismo, convencionou-se a divisão deste em três tipos de gêneros: informativo, opinativo e interpretativo. O primeiro diz respeito ao modelo noticioso consolidado ao longo dos séculos XIX e XX. Assim, as informações são transmitidas de forma a enfatizar uma suposta neutralidade que, em geral, são formatadas através dos modelos do lead e da pirâmide invertida. É uma análise factual dos acontecimentos que, supostamente, retiram do conteúdo jornalístico qualquer forma de opinião, preconceito ou crença tanto do repórter quanto da empresa de comunicação. Atorresi (1996) assinala que este gênero é caracterizado por se propor como transmissor de enunciados, direita ou indiretamente, os quais podem ser facilmente reduzidos à estrutura de uma oração simples:

El periodismo informativo procura dar a conocer lo que se refiere a un hecho ocurrido o por ocurrir ajustándose, en lo posible, a toda una serie de recursos que tienden a crear el efecto de fidelidad respecto del acontecimiento, la ilusión de Verdad (ATORRESI, 1996, p. 20).

Já o chamado jornalismo opinativo é construído para convencer e se situa em locais exclusivos para esta forma de expressão por meio de ferramentas como a crítica, a resenha, o artigo, o comentário, o editorial ou a crônica. Segundo Atorresi (1996), este gênero está circunscrito em uma retórica argumentativa na qual os juízos e razões são enlaçados mediante conectores lógicos que permitem ser demonstrados. Assim, frente à ilusão de que o vivido e o percebido é relatado objetivamente, o jornalismo opinativo 
contrapõe a explicação de uma análise subjetiva posta em funcionamento a partir da reflexão do jornalista.

A interpretação, conforme Beltrão (1976), é uma atitude de ofício do agente de informação na atualidade. Desta forma, o jornalismo interpretativo estabelece uma análise preliminar que busca submeter os dados recolhidos a uma seleção crítica, a fim de transformá-los em matéria para divulgação. Este gênero jornalístico se caracteriza por informar a população, de forma não opinativa, sobre o quadro complexo da situação do momento, realizando um "esforço de determinar o sentido de um fato, através da rede de forças que atuam nele - e não a atitude de valoração desse fato ou de seu sentido, como se faz em jornalismo opinativo" (LEANDRO \& MEDINA apud BELTRÃO, 1976, p. 48).

Na prática, essa divisão entre os gêneros não é tão nítida assim. Uma notícia, ainda que busque ser o mais factual possível, opera uma seleção que não está isolada de ações interpretativas e/ou opinativas. Como aponta Morin (1990), nosso pensamento distingue categorias com o fim de facilitar o entendimento, porém é importante reconhecer os elos existentes entre as entidades para que esta distinção não passe a ser um isolamento. Falta ao jornalismo admitir essa multidimensionalidade na medida em que - com a exceção de algumas revistas semanais e outras propostas que assimilaram um pouco de ar fresco - este ainda se propõe como isento e seguidor do manual dos gêneros divisórios no jornalismo.

Analisando o funcionamento de uma redação jornalística, Tuchman (1972) aponta que procedimentos como a apresentação de diversas versões da mesma realidade; a posse de provas suplementares para fundamentar um fato; a utilização de aspas para indicar que não é o repórter que está dando uma versão dos acontecimentos; a distribuição dos fatos a partir do mais importante; e a separação entre opinião e fato através de espaços exclusivos para as manifestações opinativas não significa que os jornalistas alcançaram a propalada objetividade. Dessa forma, o autor rebate que estes procedimentos constituem um convite à percepção seletiva; reproduzem erroneamente a noção de que 'os fatos falam por si'; são limitados pela política editorial de uma determinada organização jornalística; são um instrumento de descrédito e um meio do jornalista fazer passar sua opinião; e iludem o público leitor ao sugerir que a análise opinativa é convincente e ponderada. O autor conclui afirmando que "dá a sensação de que o termo objetividade está a ser utilizado defensivamente como ritual estratégico" (TUCHMAN, 1972, p. 90) na medida em que protege o profissional e a empresa dos erros e dos possíveis críticos acerca do que foi publicado. 
Essa concepção prática e técnica de Comunicação, que integra uma perspectiva funcional/utilitarista que supervaloriza o fazer e o sucesso econômico, está inserida no que Contrera (2009) chama de desencantamento da comunicação contemporânea, noção que se prolonga na atual produção jornalística e perpetua a separação entre sujeito e objeto postulada pela ciência moderna. Parece haver, então, um prolongamento entre verdade científica e jornalística, na medida em que ambas atividades buscam sua credibilidade na construção de uma observação neutra, desprovida da intervenção de fatores como valores pessoais, preconceitos, visões institucionais, interesses político-econômicos e sensações.

Desse modo, o modelo cartesiano da objetividade é discutível na medida em que se mostra insuficiente frente à complexidade do mundo e das relações humanas, frente à necessidade de passarmos a uma cosmovisão que não mais atrofie o homem enquanto ser eminentemente racional capaz de captar o mundo como ele é. Tanto quanto a ciência, o jornalismo não contém uma verdade absoluta, mas sim interpretações que operam através da seleção e resignificação dos eventos e fenômenos que nos cercam cotidianamente. Assim, refletir sobre os modos de constituição de discursos de verdade no fazer jornalístico mostra-se cada vez mais necessário para que possamos compreender os suportes físicos, morais e éticos que funcionam como sustentáculo de tais enunciados.

\section{REFERÊNCIAS}

AMARAL, Luiz. A objetividade jornalística. Porto Alegre: Sagra, 1996.

ATORRESI, Ana. Los generos periodisticos: antologia. Buenos Aires: Colihue, 1996.

BAHIA, Juarez. Jornal, história e técnica: história da imprensa brasileira. São Paulo: Ática, 1990.

BARROS, Ana Taís Martins Portanova. Jornalismo, narrador do entre-saberes da contemporaneidade. In: Nós transdisciplinamos: diálogos nas ciências da comunicação [recurso eletrônico]. Porto Alegre: Armazém Digital, 2007. p. 9-13.

BELTRÃO, Luiz. Jornalismo opinativo. Porto Alegre: Sulina, 1976.

CONTRERA, Malena Segura. Do lado de fora do jardim encantado: comunicação e desencantamento do mundo. E-compós. Brasília, v. 12, n. 3, set/dez. 2009.

COTRIM, Gilberto. Fundamentos de filosofia: ser, saber e fazer. São Paulo: Saraiva, 1996.

DESCARTES, René. Discurso do método; meditações; objeções e respostas; as paixões da alma; cartas; introdução de Gilles-Gaston Granger; prefácio e notas de Gerard Lebrun; tradução de J. Guinsburg e Bento Prado Júnior. 2. ed. São Paulo: Abril Cultural, 1979.

MEDINA, Cremilda de Araujo. Notícia: um produto à venda: jornalismo na sociedade urbana e indus- 
trial. 2. ed. São Paulo: Summus, 1988.

MOREL, Marco; BARROS, Mariana Monteiro de. Palavra, imagem e poder: o surgimento da imprensa no Brasil do século XIX. Rio de Janeiro: DP\&A, 2003.

MORIN, Edgar. Introdução ao pensamento complexo. 4. ed. Lisboa: Instituto Piaget, 1990. . A necessidade de um pensamento complexo. In: MENDES, Candido (org.). Representação e complexidade. Rio de Janeiro: Garamond, 2003. p. 69-78.

TUCHMAN, Gaye. A objetividade como ritual estratégico: uma análise das noções de objetividade dos jornalistas. In: TRAQUINA, Nelson (Org.). Jornalismo: questões, teorias e "estórias". 2.ed. Lisboa: Vega, 1999.

RECEBIDO EM: 31/08/12

ACEITO PARA PUBLICAÇÃO: 25/10/12

\section{Camila Mozzini}

Formada em Comunicação Social - habilitação Jornalismo pela Universidade Federal do Rio Grande do Sul (UFRGS). Atualmente é mestranda e bolsista CAPES do Programa de Pós-Graduação em Psicologia Social e Institucional da UFRGS. 